\title{
Dental Management of Hypophosphatemic Vitamin D Resistant Rickets
}

\author{
(D) Akif Demirel1, (1) Ayşe Tuba Altuğ2, (1) Esra Erdemli33, (1) Firdevs Tulga Öz1 \\ ${ }^{1}$ Ankara University Faculty of Dentistry, Department of Pediatric Dentistry, Ankara, Turkey \\ ${ }^{2}$ Ankara University Faculty of Dentistry, Department of Orthodontics, Ankara, Turkey \\ ${ }^{3}$ Ankara University Faculty of Medicine, Department of Histology Embryology, Ankara, Turkey
}

\begin{abstract}
Vitamin D-Resistant Rickets (VDRR) is an X-linked disease, causing mineralization disturbances of hard tissues such as bones and deciduous and permanent dentition. The dental findings of VDRR are enlarged pulp horns and chambers, defective enamel/dentin tissue, pulpitis, pulp necrosis, periapical recurrent abscesses and periapical complications without dental caries or trauma. The treatment options of this condition are extraction, endodontic approaches such as pulpotomy/pulpectomy, restorative and preventive applications. The aim of this case report is to summarize the dental clinical, radiographical, histopathological findings and treatment options of VDRR in a 4.5-year-old girl.

Keywords: Vitamin D Resistant Rickets, dentinal clefts, dental abscess, histopathology, primary teeth
\end{abstract}

\section{Introduction}

Vitamin D plays a vital role in the absorption of calcium and phosphate. Low levels of vitamin D can trigger the body to release hormones that lead to the eventual loss of calcium and phosphate from bones, which leads to insufficient bone mineralization. Vitamin D Resistant Rickets (VDRR) is also known as X-linked hypophosphatemia with a prevalence of 1:20.000 people (1-4). It is characterized by a calcium and phosphate metabolism disorder affecting mineralized tissues, bone and teeth $(1,5)$. VDRR was first documented by Albright et al. (6) (1937) and mineralization defects of hard tissues in these cases are derived from renal transepithelial transport disturbance resulting in decreased tubular reabsorption of phosphate and hypophosphatemia $(1,4,7)$. Physical findings are growth failure, bowing of the legs, short stature and walking disturbances $(4,7,8)$.
VDRR has been connected with several primary and permanent teeth alterations. Dental findings of this condition are enlarged pulp chambers, pulp horns which spread outside the dentino-enamel junction, enamel and dentine defects, poorly defined lamina-dura, short roots and hypoplastic alveolar ridge (4,9-11).

Histological analysis point to clefts in dental hard tissues especially dentine, marked globular dentine and increased predentin width $(2,7,9)$. The combination of all these factors contribute to recurrent dental abscesses in VDRR cases. Bacteria and their toxins which come from the oral cavity to the pulp cause pulpitis, pulp necrosis, periapical recurrent abscess or periapical complications without dental caries $(1,2,4,5,7,9-14)$.

In VDRR cases, in spite of the impairment of dentine mineralization, it is known that the odontoblastic cell function is normal $(15,16)$. Additionally, dentine tissue is more 
affected than enamel (4). Furthermore, because enamel and dentine formation occur between 4 months in-utero and 11 months of age, deciduous teeth defects cannot be avoided. However, permanent dentition development can be improved by medical therapy after birth. Therefore, mineralized tissue defects are more common in primary dentition than permanent dentition $(3,4,16)$.

This case report aims to present dental clinical, radiographic and histological features of a VDRR case at our clinic.

\section{Case Report}

A 4.5-year-old female patient was referred to our clinic with the complaint of a speech problem, including delayed speech and difficulty in making some sounds. As a result of questioning her medical history, it was discovered that she had VDRR and its physical findings (Figure 1).

Clinical dental examination revealed that there was fistula formation at the periapical area of the left maxillary primary central incisor without caries and a dental trauma history (Figure 2) and, as a result of radiographic examination, that a related tooth also had a periapical lesion (Figure 3). Additionally, the right maxillary primary central incisor had colour changes but a cold vitality test showed a positive response. Furthermore, caries of mandibular primary first molars were diagnosed both clinically and radiologically. In addition, during speech examination, problems with the ' $z / s$ ' sounds were noted and consultation with the orthodontics department showed that the patient had a "deep palatal vault".

The parents of the patient were informed about the treatment and their consent was obtained. Initially, the left maxillary primary central incisor was extracted and the mandibular first primary molars were restored with compomer (Dyract XP, Dentsply, DeTrey GmbH). After that,

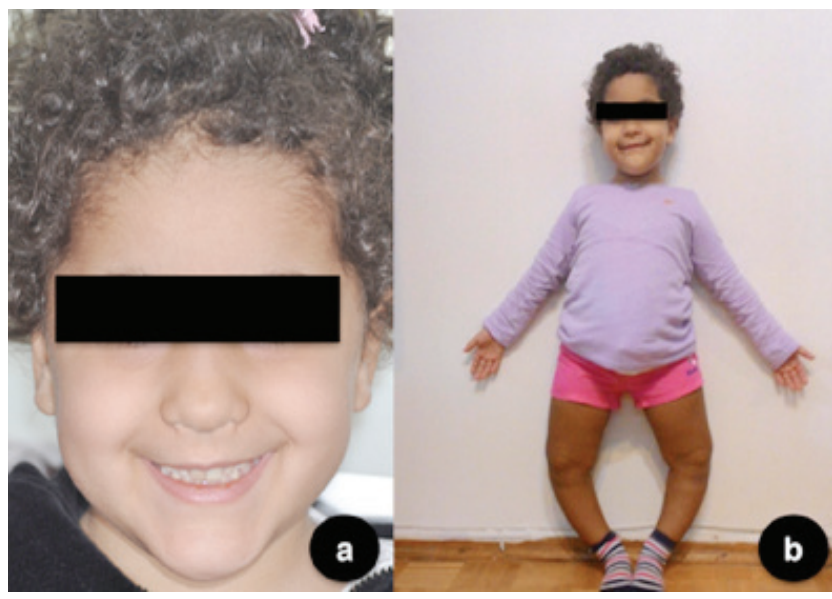

Figure 1. The patient with Vitamin D Resistant Rickets; a) facial view, b) physical findings to avoid infantile swallowing, improve speech ability and for aesthetic purposes, a removable partial child prosthesis was applied (Figure 4). Histological evaluation was carried out in order to diagnose dental manifestation of VDRR accurately. In the histological assessment, a healthy primary incisor tooth which exfoliated physiologically was used to compare with the patient's left upper primary central incisor.

After fixing the dental tissues of the extracted teeth with $10 \%$ buffered formalin, they were decalcified with $8 \%$ formic

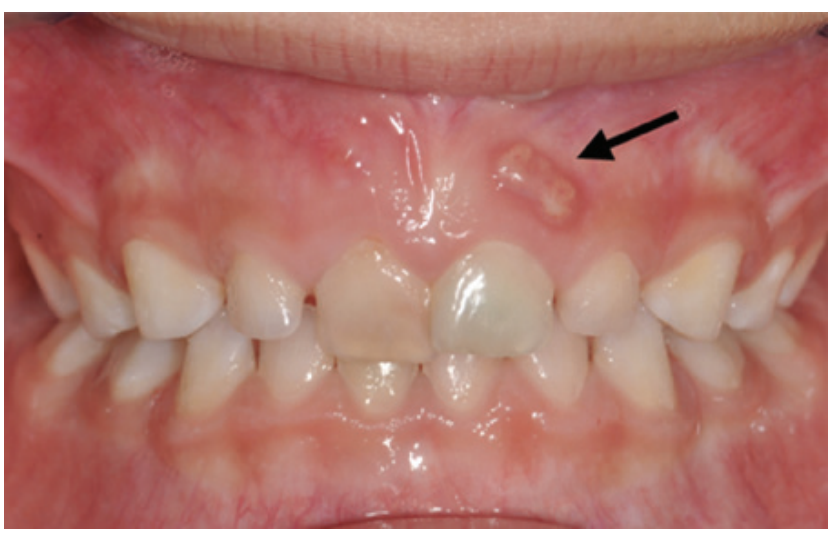

Figure 2. Intraoral view of the patient and fistula formation (arrow)

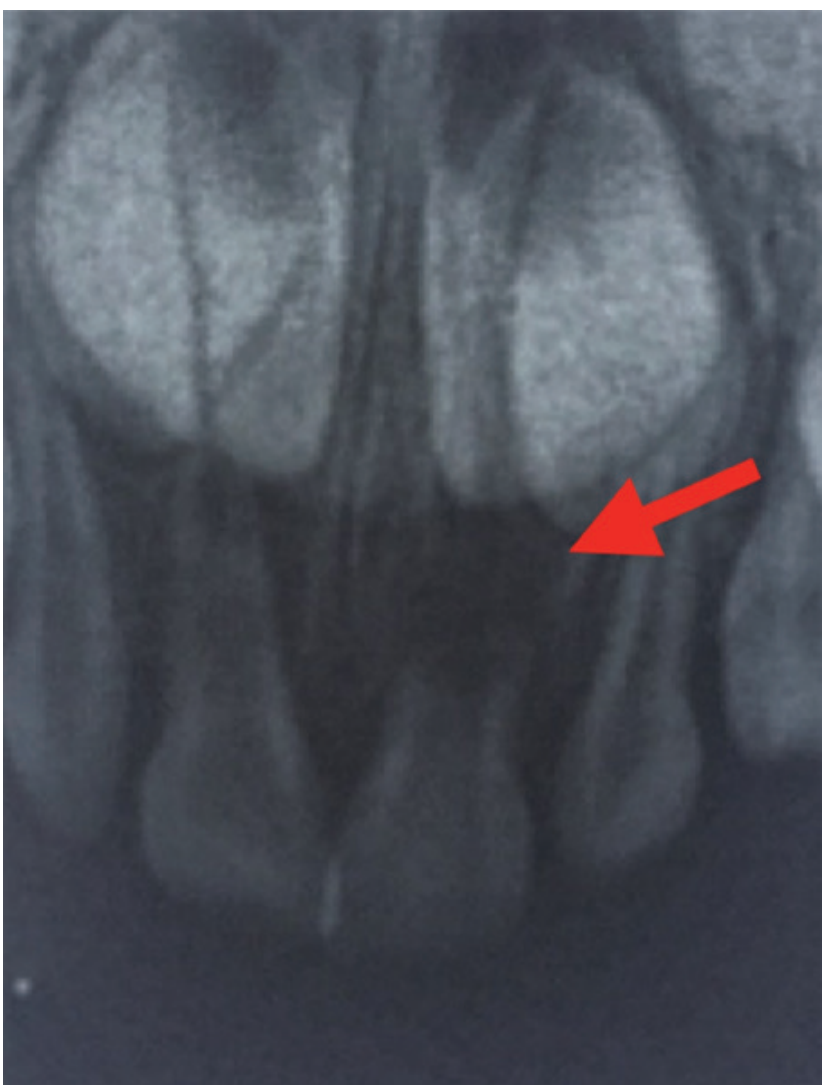

Figure 3. Periapical radiograph of the primary incisors and the radiolucency around the periapical region of tooth 61 (arrow) 
acid / 8\% hydrochloric acid. Following the routine histological preparations, the teeth were embedded paraffin sectioned to obtain sections $4 \mu \mathrm{m}$ in thickness. These sections were stained using hematoxylin-eosin and examined under a light microscope (Zeiss AxioScope A1, Carl Zeiss, Germany).

Histological assessment of the teeth showed that, although the odontoblastic cell layer was intact, the predentin layer width was increased when compared with a healthy primary incisor tooth (Figure 5). Additionally, the evaluation revealed that the specimens had increased predentin, marked globular dentine with hipomineralized areas, dentinal clefts and dilated dentinal tubules (Figures 6,7).

Finally, in order to provide oral health care, oral hygiene procedures were given to the patient and her parents. Topical fluoride varnish (Duraphat, Colgate-Palmolive, $\mathrm{GmbH}$, Hamburg, Germany) was applied to all the teeth to avoid probable pulp pathologies and the patient had follow-ups periodically.

\section{Discussion}

VDRR is a disease which is characterized by defective reabsorption of phosphate from the proximal renal tubule

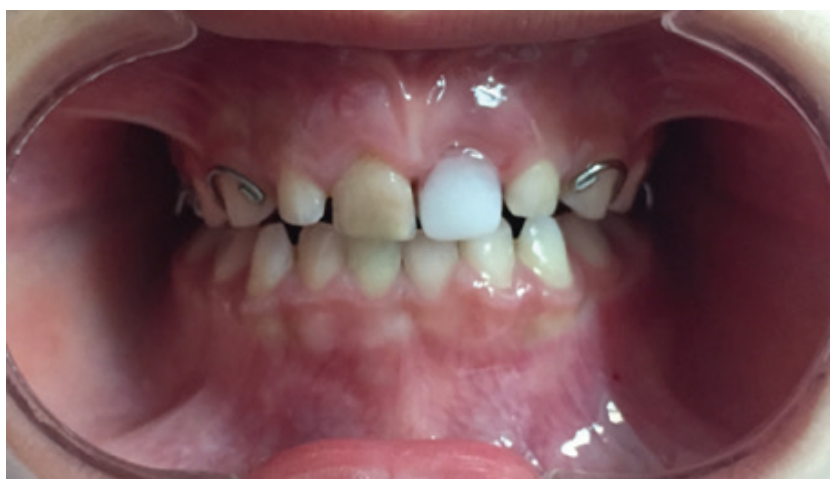

Figure 4. Removable partial child prosthesis

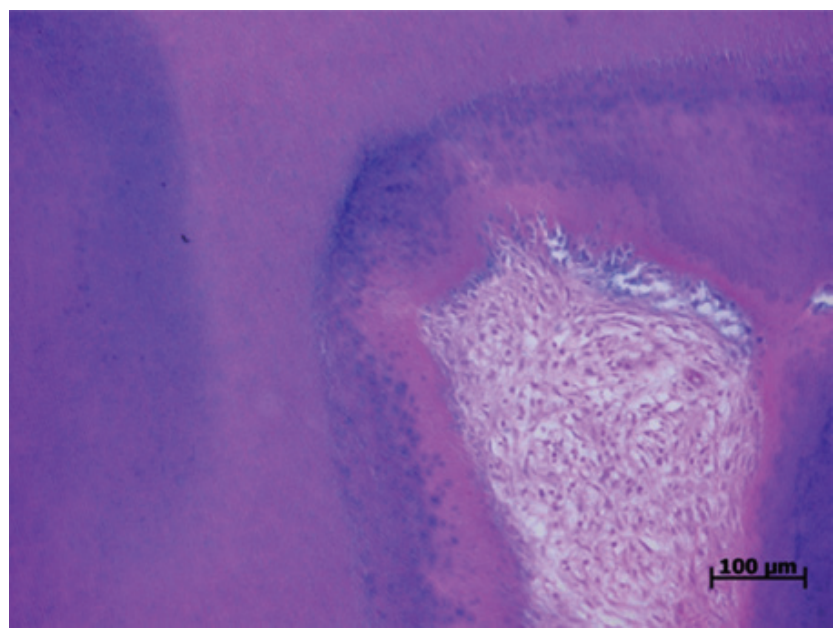

Figure 5. Histological section of healthy primary incisor as a control tooth
$(1,7,9)$. Hypophosphatemic VDRR may be less severe when it occurs in the late stages of life and does not cause bone deformity. In a study of the orthodontic treatment of a 9-year-old girl with VDRR, Kawakami and Takano-Yamamoto (17) (1997) reported that VDRR can be diagnosed by dental examination.

In this VDRR case, histological examination of the extracted tooth showed dentinal clefts/dilated dentinal tubules and these conditions agreed with the dental findings of VDRR. Furthermore, as noted in some cases $(1,7,9)$, marked globular dentine, increased predentin width and intact odontoblastic cell layer were seen in the present case. The enamel in these cases was reported to be normal but thinner contrary to defective dentin tissue $(4,11)$. However, sometimes, enamel cracks $(18,19)$ and enamel hypoplasia $(3,18,20)$ can be observed in patients.

Prophylactic pulp/endodontic treatments, conservative treatment and tooth extraction may be applied in these cases

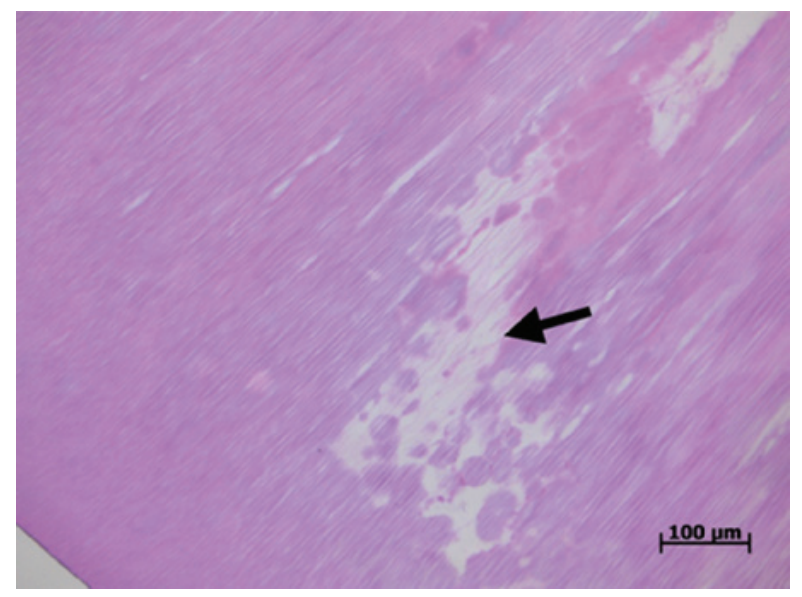

Figure 6. Histological section of the extracted tooth. Note the dentinal clefts and dilated dentin tubules (arrow) (x20 magnification)

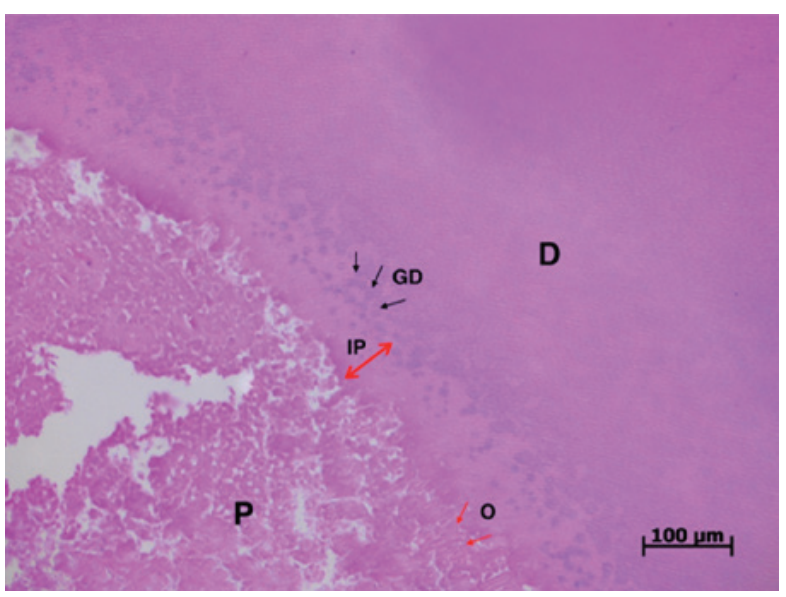

Figure 7. Histological section of the extracted tooth. Note the increased predentin width (IP-red arrow), intact odontoblasts (O - red arrows), globular marked globular dentine (GD - black arrows), P: Pulp, D: Dentine (x20 magnification) 
$(4,5,21)$. Although the prophylactic pulpotomy is one of the treatment options of VDRR cases, it is not recommended due to lack of sufficient evidence for a good prognosis (21). In this case, tooth \#61 was extracted because of a fistula formation and periradicular lesion. Following extraction, dentin caries were restored and removable denture was applied to avoid infantile swallowing, physiological and speech problems (22). Additionally, dentin caries of the mandibular first primary molars were restored with polyacid-modified composite resin (compomer) to prevent probable pulpal disease.

In addition to progressive caries and abscess formation, attrition of the dental mineralized tissues is also seen in VDRR cases (9). In these cases, to avoid attrition and microfractures of enamel and dentine, prefabricated metal or polycarbonate resin crowns can be applied (23). However, in the present case, this application was not carried out because there was no defect in the enamel and the perforation risk to the pulp chambers (16). Finally, following the therapeutic, restorative and preventive applications, the patient was recalled for periodical check-ups of the prosthetic appliance, general dental condition, orthodontic examination and caries preventing procedures.

\section{Ethics}

Informed Consent: Consent form was filled out by the parents of the patient.

Peer-review: Externally peer-reviewed.

\section{Authorship Contributions}

Surgical and Medical Practices: A.D., A.T.A., E.E., F.T.Ö., Concept: A.D., F.T.Ö., Design: A.D., F.T.Ö., Data Collection or Processing: A.D., A.T.A., Analysis or Interpretation: A.D., F.T.Ö., Literature Search: A.D., A.T.A., E.E., F.T.Ö., Writing: A.D., A.T.A.

Conflict of Interest: No conflict of interest was declared by the authors.

Financial Disclosure: The authors declared that this study received no financial support.

\section{References}

1. Pereira $C M$, Andrade $C R$, Vargas PA, Coletta RD, de Almeida OP, Lopes MA. Dental alterations associated with X-linked hypophosphatemic rickets. J Endod 2004;30:241-5.

2. Batra P, Tejani Z, Mars M. X-linked hypophosphatemia: dental and histologic findings. J Can Dent Assoc 2006;72:69-72.

3. Souza MA, Soares Junior LA, Santos MA, Vaisbich $M H$. Dental abnormalities and oral health in patients with hypophosphatemic rickets. Clinics (Sao Paulo) 2010;65:1023-6.

4. Souza AP, Kobayashi TY, Lourenço Neto N, Silva SM, Machado MA, Oliveira TM. Dental manifestations of patient with Vitamin D-resistant rickets. I Appl Oral Sci 2013;21:601-6.

5. Hernandez GG, Laguna FB. Dental characteristics of hypophospathemic rickets. Case report. Revista Odontológica Mexicana 2013;17:101-8.
6. Albright F, Butler AM, Bloomberg E. Rickets resistant to vitamin D therapy. Am I Dis Child 1937;54:529-47.

7. Tümen EC, Yavuz I, Suer Tümen D, Atakul F. Dental and histologic findings of $\mathrm{X}$-linked hypophosphatemic vitamin D-resistant rickets: A case report. International Dental and Medical Disorders 2008;1:37-42.

8. Zambrano M, Nikitakis NG, Sanchez-Quevedo MC, Sauk IJ, Sedano $\mathrm{H}$, Rivera $\mathrm{H}$. Oral and dental manifestations of vitamin D-dependent rickets type I: report of a pediatric case. Oral Surg Oral Med Oral Pathol Oral Radiol Endod 2003;95:705-9.

9. Murayama T, Iwatsubo R, Akiyama S, Amano A, Morisaki I. Familial hypophosphatemic vitamin D-resistant rickets: dental findings and histology study of teeth. Oral Surg Oral Med Oral Pathol Oral Radiol Endod 2000;90:310-6.

10. Cremonesi I, Nucci C, D'Alessandro G, Alkhamis N, Marchionni S, Piana G. X-linked hypophosphatemic rickets: Enamel abnormalities and oral clinical findings. Scanning 2014;36:45661.

11. S Sarat G, Priyanka N, Prabhat MP, Raja Lakshmi C, Bhavana SM, Ayesha Thabusum D. Hypophosphatemic Rickets in Siblings: A Rare Case Report. Case Rep Dent 2016;2016:4803167.

12. Seow WK. Diagnosis and management of unusual dental abscesses in children. Aust Dent I 2003;48:156-68.

13. Goodman JR, Gelbier MJ, Bennett JH, Winter GB. Dental problems associated with hypophosphataemic Vitamin D resistant rickets. Int J Paediatr Dent 1998;8:19-28.

14. Andersen MG, Beck-Nielsen SS, Haubek D, Hintze $H$, Gjørup $H$, Poulsen S. Periapical and endodontic status of permanent teeth in patients with hypophosphatemic rickets. I Oral Rehabil 2012;39:144-50

15. Abe $\mathrm{K}$, Ooshima $\mathrm{T}$, Tong $\mathrm{SML}$, Yasufuku $\mathrm{Y}$, Sobue $\mathrm{S}$. Structural deformities of deciduous teeth in patients with hypophosphatemic vitamin D-resistant rickets. Oral Surg Oral Med Oral Pathol Oral Radiol Endod 1988;65:191-8.

16. Tümen EC, Yavuz I, Atakul F. Types of rickets, dental and histologic findings: Review of the literature. Pesq Bras Odontoped Clin Integr 2009;9:241-6.

17. Kawakami M, Takano-Yamamoto T. Orthodontic treatment of a patient with hypophosphatemic vitamin D-resistant rickets. ASDC J Dent Child 1997;64:395-9.

18. Baroncelli Gl, Angiolini M, Ninni E, Galli V Saggese R, Giuca MR. Prevalence and pathogenesis of dental and periodontal lesions in children with $X$ linked hypophatemic rickets. Eur I Paediatr Dent 2006;7:61-6.

19. Linglart A, Biosse-Duplan M, Briot $K$, et al. Therapeutic management of hypophosphatemic rickets from infancy to adulthood. Endocr Connect 2014;14:13-30.

20. Davit-Béal T, Gabay J, Antoniolli P, Masle-Farquhar J, Wolikow M. Dental complications of rickets in early childhood: Case report on 2 young girls. Pediatrics 2014;133:1077-81.

21. Shroff DV, McWhorter AG, Seale NS. Evaluation of aggressive pulp therapy in a population of vitamin D-resistant rickets patients: a follow up of 4 cases. Pediatr Dent 2002;24:347-9.

22. Dominguez A, Aznar T. Removable prostheses for preschool children: report of two cases. Quintessence Int 2004;35:397400.

23. YasufukuY, Kohno N, Tsutsumi N, Ooshima T, Sobue S, Murakami Y, Ikari H. Dental management of familial hypophosphatemic vitamin D-resistant rickets: report of case. ASDC I Dent Child 1983;50:300-4. 